\title{
Posterior Spinal Reconstruction with Pedicle Screws, Multiple lliac Screws and Wisconsin Spinal Wires in a Patient with Neurofibromatosis Scoliosis: A Case Report
}

\author{
Woong-Beom Kim, Young-Seop Park, Jong-Hwa Park, Seung-Jae Hyun \\ Department of Neurosurgery, Spine Center, Seoul National University Bundang Hospital, Seoul National University \\ College of Medicine, Gyeonggi-do, Korea
}

A 54-year-old female with neurofibromatosis type 1 presented with progressing truncal shift owing to spinal deformity. On plain radiograph, the Cobb angle was 54 degree in coronal plane. Radiological examinations showed severe dystrophic change with dysplastic pedicles, bony scalloping, neural foraminal widening from dural ectasia. The patient underwent deformity correction and reconstruction surgery from the T9 to the pelvis using multiple iliac screws and Wisconsin interspinous segmental instrumentation by wiring due to maximize fixation points. The postoperative course was uneventful. One-year follow-up radiographs showed a successful curve correction with solid fusion. We report a case of pedicle dysplasia and dystrophic change treated by posterior segmental spinal instrumentation and fusion with help of multiple iliac screws and modified Wisconsin interspinous segmental wiring.

Key Words: Neurofibromatosis $\cdot$ Ectasia $\cdot$ Deformities $\cdot$ Scoliosis $\cdot$ Wisconsin wire

\section{INTRODUCTION}

Neurofibromatosis type 1 (NF-1) is an autosomal dominant hereditary disease and up to half of patients, orthopedic disorders are present, especially scoliosis, which is the most common skeletal manifestation ${ }^{1,5,10,13,14)}$. These spinal deformities usually divided into dystrophic and non-dystrophic groups depending on the absence or presence of three or more bony dystrophic elements ${ }^{9}$. The treatment outcome of dystrophic scoliosis in neurofibromatosis type 1 are less satisfactory than other scoliotic types due to the particular pathogenesis and clinical characteristics including neurofibromas adjacent to the spinal cord, poor bone quality with significant multiplanar spinal deformities ${ }^{6,14)}$. Therefore, surgical treatment of dystrophic scoliosis usually includes circumferential fusion to enhance stability and to make solid fusion ${ }^{17}$. But in case of severe dys-

\footnotetext{
- Received: April 14, 2015 - Revised: July 29, 2015

- Accepted: August 14, 2015

Corresponding Author: Seung-Jae Hyun, MD, PhD

Department of Neurosurgery, Spine Center, Seoul National University

Bundang Hospital, Seoul National University College of Medicine, 82,

Gumi-ro 173beon-gil, Bundang-gu, Seongnam-si, Gyeonggi-do 13620, Korea

Tel: +82-31-787-7164, Fax: +82-31-787-4059

E-mail: hyunsj@snu.ac.kr

囚This is an Open Access article distributed under the terms of the Creative Commons Aftribution Non-Commercial License (http://creativecommons.org/ licenses/by-nc/3.0/) which permits unrestricted non-commercial use, distribution, and reproduction in any medium, provided the original work is properly cited.
}

plastic scoliosis patients, especially pedicle dysplasia with massive dural ectasia, circumferential fusion is sometimes too risky to obtain. We report a successfully treated patient of deformity surgery using multiple iliac screws and Wisconsin wire.

\section{CASE REPORT}

A 54-year-old female presented with low back pain and deformity of the spine for the past twenty years. Before one year to visit our clinic, back and buttock pain was gradually being aggravated especially when she lay down or sat up. On physical examination, multiple café-au-lait spots and neurofibromas were found over her body. Plain radiographs and computerized tomographic (CT) myelogram confirmed the presence of scoliosis with truncal shift to the left side and bony scalloping from L2 to S2 with dural ectasia (Fig. 1). Cutaneous neurofibromas, café-au-lait spots, and kyphoscoliosis were corre- sponded to the diagnostic criteria of NF-1 (Table 1). Bone mineral density examination showed severe osteoporosis (T- score: -4.9). Progressive truncal shifting and axial back pain made us decide to undergo a deformity correction surgery. With prone position on Jackson table, posterior segmental spinal instrumentation and fusion was performed from T9 to the pelvis. Dural ectasia and osseous dysplasia precluded the use of pedicle screws from L2 to the pelvis. Because insufficient insertion points for pedicle screws, we used multiple iliac screws and modified Wisconsin interspinous 

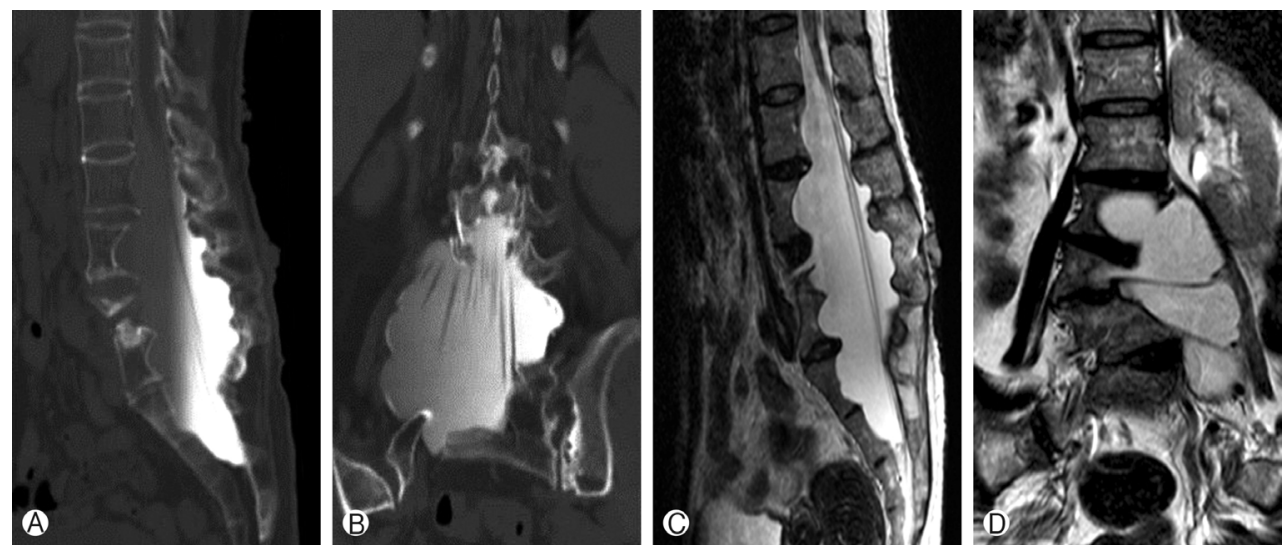

Fig. 1. Lumbar spine sagittal and coronal CT myelogram (A, B) and MRI (C, D) showing the osseous dysplasia and the dural ectasia from $L 2$ to sacrum.

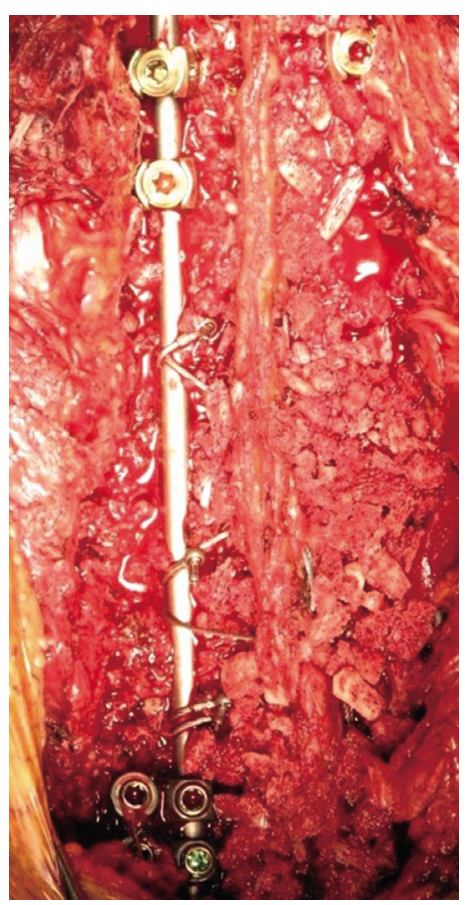

Fig. 2. Wisconsin wire connecting the spinous process and the rod.

Table 1. Diagnostic criteria for neurofibromatosis type 1

Diagnostic Criteria for NF-1

- First degree relative afflicted with NF-1

- 6 or more café-au-lait spots $(0.5 \mathrm{~cm}$ in prepubertal individuals, $>1.5 \mathrm{~cm}$ in postpubertal individuals)

- Axillary or inguinal freckling (Crowe sign)

- 2 or more cutaneous neurofibromas or at least 1 plexiform neurofibroma

- 2 or more iris Lisch nodules

- Optic nerve glioma

- A characteristic bony lesion (pseudarthrosis, sphenoid bone dysplasia, severe kyphoscoliosis)

In order to make the diagnosis, at least 2 major criteria are required segmental wiring technique to obtain adequate fixation points and to achieve solid fusion. Thirteen total fixation points were established with eight bilateral pedicle screws from T9 to T12, unilateral screws on L1 and four iliac screws. Wisconsin wires (titanium cable) were applied to link the spinous process to the left side rod with help of miniplates to prevent bone cutting by the cable (Fig. 2). After decortication of posterior bony element of spine, autologous bone chips and demineralized bone matrix mixed allograft bone chips were implanted. After deformity correction surgery, thoracic-lumbo-sacral orthosis was applied for three months in order to protect excessive strains and prevent dislodgement of the implants. Corrected spinal curve was well preserved during one-year follow-up period with solid fusion without neurologic deficit (Fig. 3 and 4). Ultimate follow-up Scoliosis Research Society-22r score was significantly improved comparing to that of preoperative score (Fig. 5).

\section{DISCUSSION}

Spinal deformity is a common feature of neurofibromatosis type 1 and the dystrophic lesion like dural ectasia aggravates the deformity more rapidly that provokes severe spinal instability and structural problems. Although the deformity is severe, there were no neurologic deficits as a result of a widened spinal canal due to the ectatic thecal $\mathrm{sac}^{16}$. Dystrophic scoliotic curves less than $20^{\circ}$ should be closely observed with short intervals to identify sudden and rapid progression ${ }^{8}$. For patients with $20-40^{\circ}$ scoliosis with less than $50^{\circ}$ of kyphosis, posterior spinal arthrodesis using segmental fixation with either multiple sublaminar wires or rod-hook constructs and the application of plentiful bone graft is strongly indicated ${ }^{14)}$.

Apart from this selective group of patients that can be treated with isolated posterior instrumented fusion, for most dystro- 

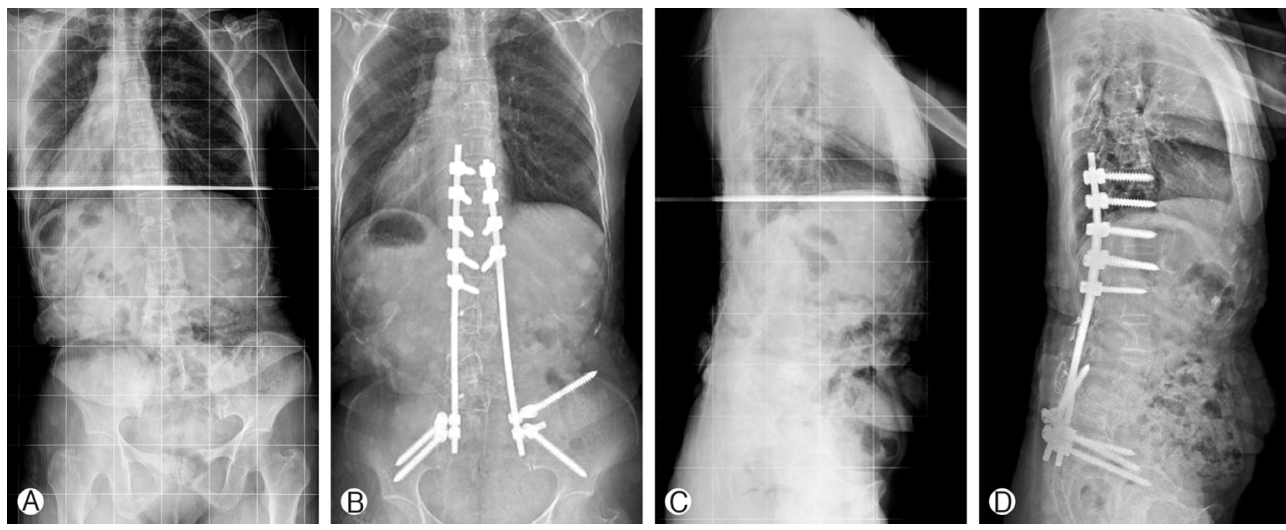

Fig. 3. One-year follow-up plain radiograph $(B, D)$ shows the successful correction of the spinal deformity comparing to preoperative plain radiograph $(A, C)$.
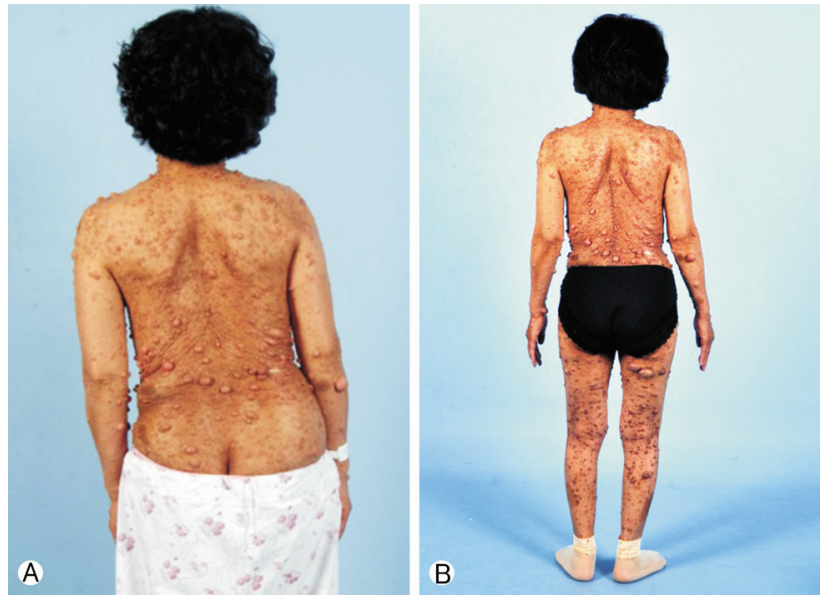

Fig. 4. The clinical photographs showing a well-balanced trunk. (A) Preoperative, (B) One year after surgery.

phic NF spine, circumferential fusion with anterior column support shows high fusion rate, good curve correction, and good functional outcome $e^{12,15,18,19,20)}$. Thus, previous literatures recommend circumferential fusion and instrumentation as the most reliable surgical option in patients of thoracic kyphosis that exceeds 50 degrees $^{17}$. Anterior autologous strut graft could reinforce the vertebral column followed by posterior instrumentation with copious amount of autologous iliac crest bone ${ }^{11,12)}$. Nevertheless, the lack of the sufficient anterior bony structure from the dural ectasia and concerns for inevitable dural injury and uncontrollable leakage of cerebrospinal fluid made us decide posterior only surgery in this particular case. Because of dysplastic pedicle, we could not use the pedicle screws from L2 to sacrum. Moreover, anterior spinal fusion was not feasible. Thus, multiple iliac screws were inevitably needed to obtain more fixation points to enhance stability. Multiple iliac screws were previously introduced as a method

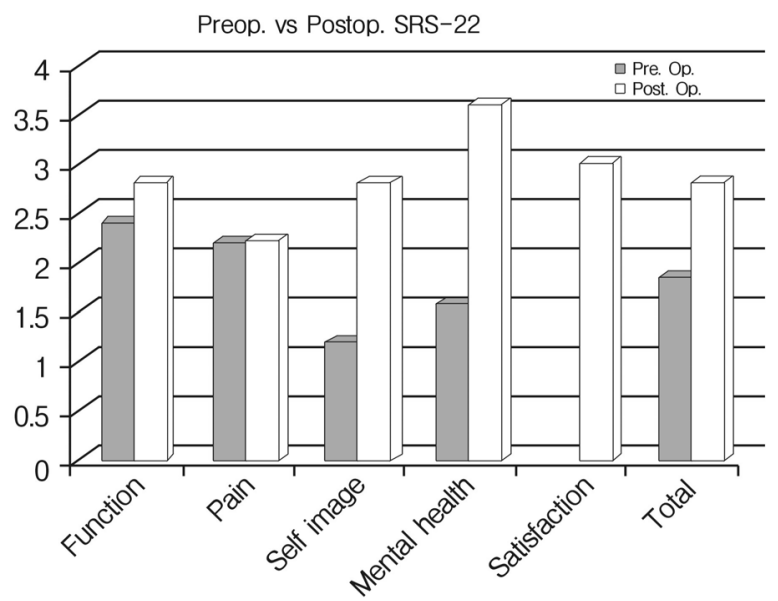

Fig. 5. Scoliosis Research Society-22r score showing significantly improved comparing to that of preoperative score.

for spinopelvic reconstruction after sacrectomy.

After rod implantation, we used modified Wisconsin interspinous segmental wiring technique connecting the spinous processes and the rod using titanium cable and miniplates ${ }^{7}$. Because of the disadvantages of the sublaminar wiring such as poor anchoring, and an increased risk of neurological injury, the usefulness of Wisconsin wiring has been recognized for better stabilization and avoiding the neurologic injury ${ }^{4,7,17}$. Moreover, considering her osteoporosis, we modified the Wisconsin interspinous segmental wiring technique using miniplates to prevent bone cutting by the cable.

There were some successful deformity correction and fusion cases by using recombinant human bone morphogenetic protein (rh-BMP) ${ }^{2,3)}$. However, in Republic of Korea, rh-BMP is not officially available yet. Thus, we used autologous local bone, allograft bone chip and demineralized bone matrix for fusion. 


\section{CONCLUSION}

Modified Wisconsin interspinous segmental wiring technique and multiple iliac screws with posterior segmental spinal instrumentation and fusion could be a reasonable surgical method in selected cases of severe pedicle dysplasia.

\section{ACKNOWLEDGMENT}

This study was approved by a local ethical committee (IRB number: B-1410-272-114).

\section{REFERENCES}

1. Akbarnia BA, Gabriel KR, Beckman E, Chalk D: Prevalence of scoliosis in neurofibromatosis. Spine (Phila Pa 1976) 17:244248, 1992

2. Benglis $\mathrm{D}$, Wang MY, Levi $\mathrm{AD}$ : A comprehensive review of the safety profile of bone morphogenetic protein in spine surgery. Neurosurgery 62:423-431, 2008

3. Cho SK, Stoker GE, Bridwell KH: Spinal reconstruction with pedicle screw-based instrumentation and rhBMP-2 in patients with neurofibromatosis and severe dural ectasia and spinal deformity: report of two cases and a review of the literature. J Bone Joint Surg Am 93:1-8, 2011

4. Cho SK, Kim YJ: History of spinal deformity surgery part I: The Pre-modern Era. Korean J Spine 8:1-8, 2011

5. Cnossen MH, de Goede-Bolder A, van den Broek KM, Waasdorp $\mathrm{CM}$, Oranje AP, Stroink H, et al: A prospective 10 year follow up study of patients with neurofibromatosis type 1 . Arch Dis Child 78:408-412, 1998

6. Crawford AH: Pitfalls of spinal deformities associated with neurofibromatosis in children. Clin Orthop Relat Res 245:2942, 1989

7. Drummond D, Guadagni J, Keene JS, Breed A, Narechania R: Interspinous process segmental spinal instrumentation. J Pediatr Orthop 4:397-404, 1984

8. Feldman DS, Jordan C, Fonseca L: Orthopaedic manifestations of neurofibromatosis type 1. J Am Acad Orthop Surg 18:346-
357,2010

9. Funasaki H, Winter RB, Lonstein JB, Denis F: Pathophysiology of spinal deformities in neurofibromatosis. An analysis of seventy-one patients who had curves associated with dystrophic changes. J Bone Joint Surg Am 76:692-700, 1994

10. Gutmann DH, Aylsworth A, Carey JC, Korf B, Marks J, Pyeritz $\mathrm{RE}$, et al: The diagnostic evaluation and multidisciplinary management of neurofibromatosis 1 and neurofibromatosis 2. JAMA 278:51-57, 1997

11. Halmai V, Doman I, De Jonge T, Illes T: Surgical treatment of spinal deformities associated with neurofibromatosis type 1 . Report of 12 cases. J Neurosurg 97:310-316, 2002

12. Iwai $C$, Taneichi $H$, Inami $S$, Namikawa $T$, Takeuchi $D$, Kato $\mathrm{N}$, et al: Clinical outcomes of combined anterior and posterior spinal fusion for dystrophic thoracolumbar spinal deformities of neurofibromatosis-1: fate of nonvascularized anterior fibular strut grafts. Spine (Phila Pa 1976) 38:44-50, 2012

13. Jett K, Friedman JM: Clinical and genetic aspects of neurofibromatosis 1. Genet Med 12:1-11, 2010

14. Kim HW, Weinstein SL: Spine update: the management of scoliosis in neurofibromatosis. Spine (Phila Pa 1976) 22:27702776, 1997

15. Koptan W, Miligui Y: Surgical correction of severe dystrophic neurofibromatosis scoliosis: an experience of 32 cases. Eur Spine J 19:1569-1575, 2010

16. Lykissas MG, Schorry EK, Crawford AH, Gaines S, Rieley M, Jain VV: Does the presence of dystrophic features in patients with type 1 neurofibromatosis and spinal deformities increase the risk of surgery? Spine (Phila Pa 1976) 38:1595-1601, 2013

17. Lykissas MG, Aichmair A: Current concepts on spinal arthrodesis in degenerative disorders of the lumbar spine. World J Clin Cases 1:4-12, 2013

18. Parisini P, Di Silvestre M, Greggi T, Paderni S, Cervellati S, Savini R: Surgical correction of dystrophic spinal curves in neurofibromatosis. A review of 56 patients. Spine (Phila Pa 1976) 24:2247-2253, 1999

19. Shahcheraghi GH, Tavakoli AR: Corpectomy and circumferential spinal fusion in dystrophic neurofibromatous curves. J Child Orthop 4:203-210, 2010

20. Winter RB: Severe neurofibromatosis kyphoscoliosis, posterior wedge osteotomy, halo-traction, and anterior autograft strut fusion, with 28-year follow-up. Spine (Phila Pa 1976) 36:17741777, 2011 